\title{
Living-donor lobar lung transplantation for bronchiolitis obliterans after Stevens-Johnson syndrome
}

\author{
Hiroshi Date, MD, ${ }^{a}$ Yoshifumi Sano, MD, ${ }^{a}$ Motoi Aoe, MD, ${ }^{a}$ Keiji Goto, MD, ${ }^{b}$ Takeo Tedoriya, MD, ${ }^{c}$ \\ Shunji Sano, MD, ${ }^{\mathrm{c}}$ Akio Andou, MD, and Nobuyoshi Shimizu, MD, ${ }^{a}$ Okayama, Japan
}

S

tevens-Johnson syndrome (SJS) is an acute self-limited eruption of the skin and mucous membranes that represents a hypersensitivity reaction to various etiologic agents. ${ }^{1}$ Underlying causes include exposure to drugs, various microbial diseases, malignant tumors, and connective tissue diseases. Specific involvement of bronchial epithelium is relatively uncommon but indicates a poor prognosis. ${ }^{2}$ As a consequence of airway epithelial injury, bronchiolitis obliterans can occur. $^{3}$

To our knowledge, this is the first reported case of living-donor lobar lung transplantation for bronchiolitis obliterans associated with SJS.

From the Departments of Surgery II, ${ }^{\mathrm{a}}$ Anesthesiology and Resuscitology, ${ }^{\mathrm{b}}$ and Cardiovascular Surgery, ${ }^{\mathrm{c}}$ Okayama University School of Medicine, Okayama, Japan.

Received for publication July 11, 2001; accepted for publication July 26, 2001.

Address for reprints: Hiroshi Date, MD, Department of Surgery II, Okayama University School of Medicine, 2-5-1 Shikata-Cho, Okayama 700-8558, Japan (E-mail: hdate@ nigeka2.hospital.okayama-u.ac.jp).

J Thorac Cardiovasc Surg 2002;123:389-91

Copyright $\odot 2002$ by The American Association for Thoracic Surgery

$0022-5223 / 2002 \$ 35.00+0 \quad \mathbf{1 2 / 5 4 / 1 1 9 3 3 1}$

doi: $10.1067 / \mathrm{mtc} .2002 .119331$

\section{Clinical Summary}

A 13-year-old boy who was well until September 16, 2000, received oral medication (cefcapene pivoxil hydrochloride, amantadine hydrochloride) for an upper respiratory tract infection. Twenty-four hours later, he had redness in both eyes followed by a generalized erythematous maculopapular skin rash with highgrade intermittent fever. The rash progressed to become vesiculobullous, affecting more than $80 \%$ of the body surface area. SJS was diagnosed clinically and the boy was treated with corticosteroid drugs. However, hematuria developed and mechanical ventilation was instituted on September 23 because of massive hemoptysis. The chest computed tomographic scan demonstrated parenchymal infiltrates caused by pulmonary hemorrhage (Figure 1, A). Bronchoscopic examination revealed ulcerative and exudative lesions with sloughing of mucosa throughout the respiratory tree. Therapy was continued with oral prednisolone $(80 \mathrm{mg} /$ day $)$ and there was gradual improvement of skin lesions and respiratory status. Although mechanical ventilatory support was discontinued after a month, he became completely bedridden and required supplemental oxygen inhalation continuously. In March 2001, the chest radiograph revealed bilateral hyperlucencies but no significant opacities. The chest computed tomographic scan demonstrated extensive bilateral parenchymal lung disease with pneumatocele formation (Figure 1, B).

The patient was transferred to Okayama University Hospital on March 25, 2001, for possible living-donor lobar lung transplantation. On admission, the patient was sitting on the bed with 

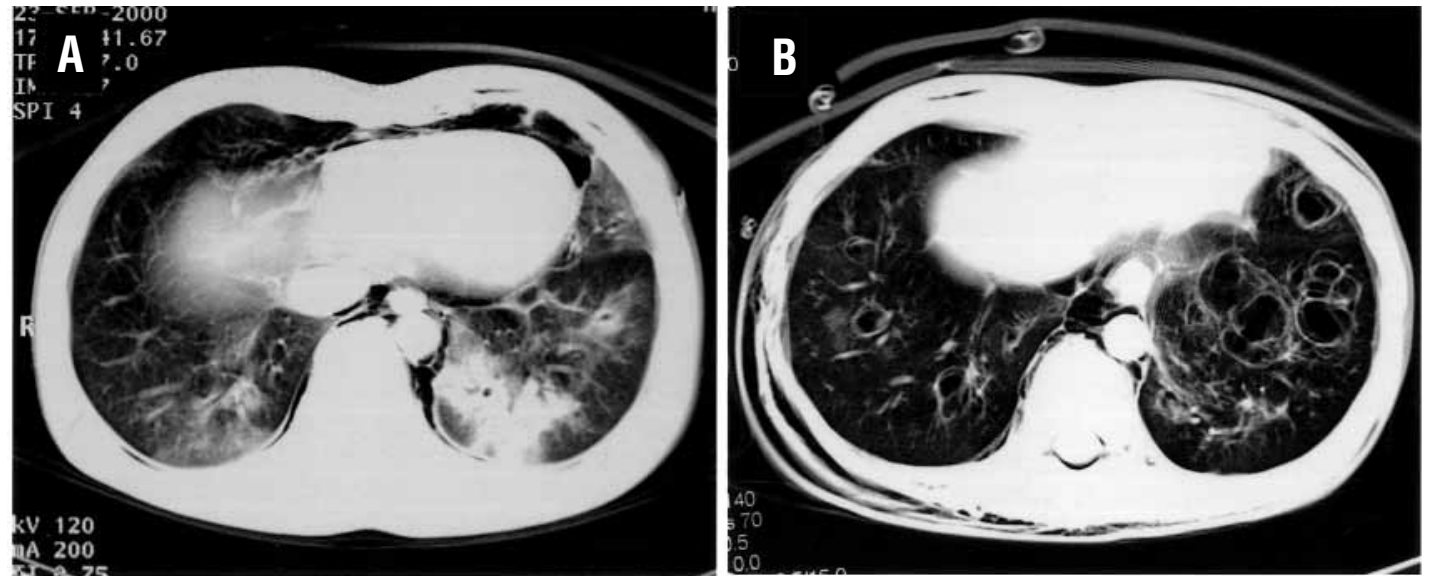

Figure 1. Preoperative computed tomographic scan of the patient with SJS-associated bronchiolitis obliterans. A, Parenchymal infiltrates due to pulmonary hemorrhage in September 2000. B, Pneumatocele formation in March 2001.

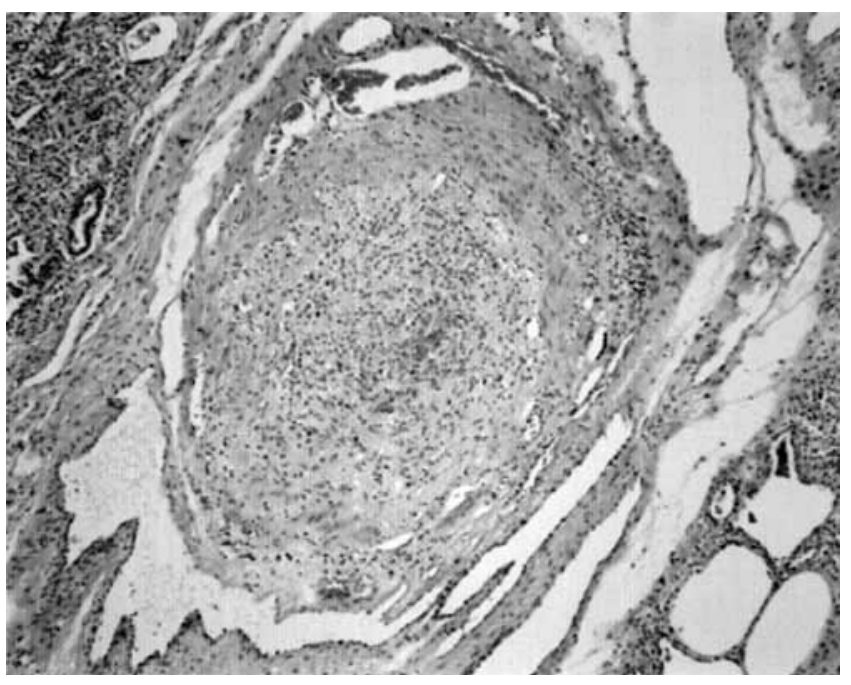

Figure 2. Histologic examination of the excised lung tissue, showing bronchiolitis obliterans with total scarring. The lumen of the bronchiole was obliterated by dense fibrous scar tissue associated with an inflammatory mononuclear infiltrate (hematoxylineosin stain, original magnification $\times 50$ ).

his face pressed deeply down on the pillow. There was marked nasal flaring with intercostal, subcostal, and supraclavicular retractions. Auscultation revealed bilateral diffuse wheezing. An arterial blood gas revealed a $\mathrm{pH}$ of 7.31, $\mathrm{a} \mathrm{PaO}_{2}$ of $126.7 \mathrm{~mm} \mathrm{Hg}$, and $\mathrm{PaCO}_{2}$ of $100.2 \mathrm{~mm} \mathrm{Hg}$ with $7 \mathrm{~L} / \mathrm{min}$ oxygen administered via a nasal cannula.

On March 27, 2001, he underwent living-donor lobar lung transplantation with a right lower lobe from his father (36 years old) and a left lower lobe from his mother (36 years old). The heights and weights were $157 \mathrm{~cm}$ and $32.3 \mathrm{~kg}$ for the recipient, 180 $\mathrm{cm}$ and $92.0 \mathrm{~kg}$ for the father, and $160 \mathrm{~cm}$ and $52.0 \mathrm{~kg}$ for the mother.

Because of the recipient's poor preoperative condition, partial cardiopulmonary bypass was initiated by way of the femoral ves-

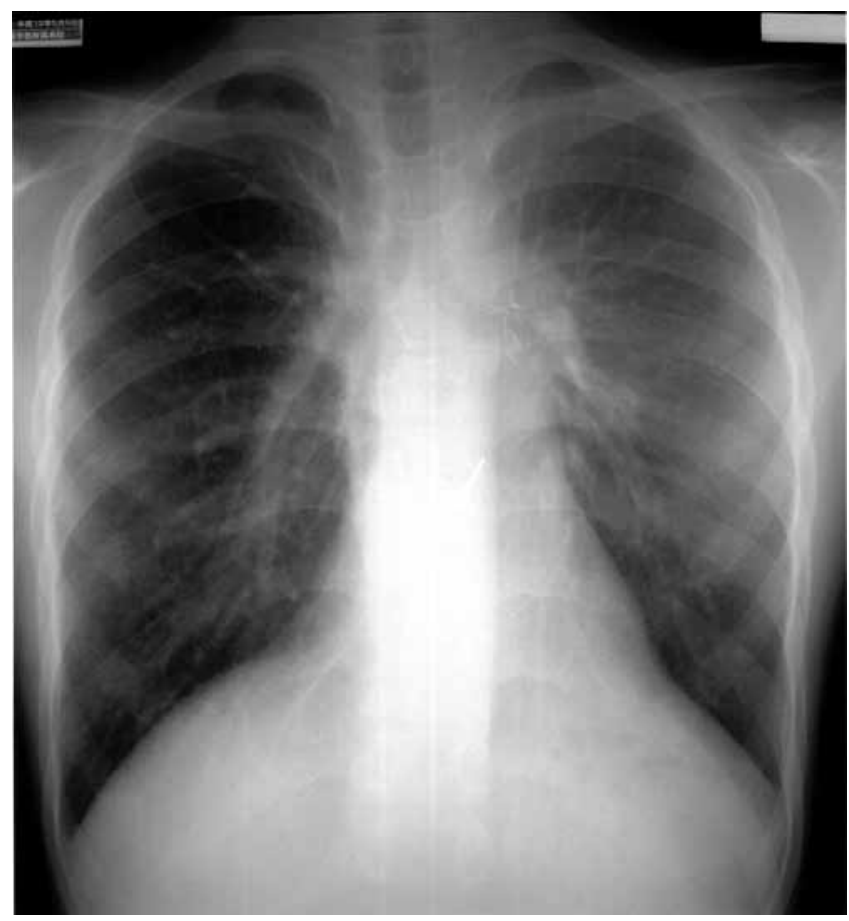

Figure 3. Chest x-ray film 1 month after living-donor lobar lung transplantation. Well-expanded grafts filled the chest cavity, leaving no detectable dead space without cardiomegaly.

sels under local anesthesia. Then, the recipient was anesthetized and intubated. The surgical and logistic aspects of the right and left donor lobectomy, the donor lobe backtable preservation technique, and the recipient bilateral pneumonectomy and bilateral lobar implantation have been previously described by Starnes' group. ${ }^{4}$

Histologic section of the excised lung tissue revealed bronchiolitis obliterans with total scarring (Figure 2). The lumen of the bronchiole was obliterated by dense fibrous scar tissue associated with an inflammatory mononuclear infiltrate. 
The postoperative course was relatively uneventful. Immunosuppression comprised a triple drug therapy consisting of cyclosporine, azathioprine, and prednisone. The patient was completely weaned from the respirator within 2 days. An episode of acute rejection required high-dose methylprednisolone intravenously. One month postoperatively, the chest $\mathrm{x}$-ray film demonstrated well-expanded grafts with no detectable dead space (Figure 3). The patient was discharged from the hospital 46 days after transplantation. Three months postoperatively, he had returned to normal life and was able to carry out daily activities. He is in good physical condition with a vital capacity of $1.75 \mathrm{~L}(66.3 \%$ of predicted), a forced expiratory volume in 1 second of $1.48 \mathrm{~L}$, and an arterial oxygen tension of $102.9 \mathrm{~mm} \mathrm{Hg}$ while breathing room air.

\section{Discussion}

SJS is a severe mucocutaneous eruption that can feature visceral involvement and cause significant morbidity and mortality. ${ }^{1}$ Both infectious agents and medications can cause SJS. In this case, drugs (cefcapene pivoxil hydrochloride, amantadine hydrochloride) for an upper respiratory tract infection were the offending agents. The immunopathogenesis of SJS is believed to involve keratinocyte apoptosis, a scenario similar to graft-versus-host disease. ${ }^{5}$ When greater than $30 \%$ of the total body surface area is involved, the disease is called toxic epidermal necrolysis. Lebargy and associates ${ }^{2}$ evaluated the incidence and prognosis of pulmonary complications associated with toxic epidermal necrolysis in 41 consecutive patients. They reported that 10 (24\%) patients had bronchial injury and 7 (17\%) patients died. The pathogenesis of chronic pulmonary sequelae in SJS or toxic epidermal necroly- sis is not well understood. Whether the cause is primary infection, mucosal damage due to immune complex deposition, or a combination of both is unclear.

There were obvious concerns regarding whether lung transplantation would be feasible for this particular patient. SJS could recur, because many kinds of medication would be used during and after transplantation. We avoided the use of cephalosporins and antipyretic drugs. Since the patient had had a hypersensitivity reaction to some drugs, immediate rejection of the lung grafts might occur. An acute rejection episode on day 8 was easily managed by bolus injection of methylprednisolone. Bronchiolitis obliterans might recur in a more accelerated manner after transplantation because this condition is known to be a feature of chronic rejection. Close monitoring of pulmonary function is mandatory.

\section{References}

1. Stitt VJ Jr. Stevens-Johnson syndrome: a review of the literature. $J$ Natl Med Assoc. 1988;80:104-8.

2. Lebargy F, Wolkenstein P, Gisselbrecht M, Lange F, Fleury-Feith J, Delclaux C, et al. Pulmonary complications in toxic epidermal necrolysis: a prospective clinical study. Intensive Care Med. 1997;23:123744.

3. Kim MJ, Lee KY. Bronchiolitis obliterans in children with StevensJohnson syndrome: follow-up with high resolution CT. Pediatr Radiol. 1996;26:22-5.

4. Starnes VA, Barr ML, Cohen RG, Hagen JA, Wells WJ, Horn MV, et al. Living-donor lobar lung transplantation experience: intermediate results. J Thorac Cardiovasc Surg. 1996;112:1284-91.

5. Inachi S, Mizutani H, Shimizu M. Epidermal apoptotic cell death in erythema multiforme and Stevens-Johnson syndrome. Arch Dermatol. 1997;133:845-9. 